\title{
Динамика частотно-модулированных волновых пакетов в условиях синхронизированного взаимодействия с бегущей волной показателя преломления
}

\author{
И.О. Золотовский" \\ Д.И. Семенцов, А.А. Фотиади, М.С. Явтушенко \\ Ульяновский государственный университет \\ "E-mail: rafzol.14@mail.ru
}

DOI:10.31868/RFL2018.116-117

В работе рассматривается формирование ультракоротких лазерных импульсов в цилиндрическом световоде из квазинепрерывной фоновой туннелирующей волны типа моды шепчущей галереи (МШГ). Эффект достигается в результате синхронизированного взаимодействия фоновой волны МШГ с бегущей вдоль оси световода волной изменения показателя преломления (БВПП) и развития модуляционной неустойчивости $(\mathrm{MH})$.

Если свет вводится в волновод под некоторым углом к образующей цилиндра, то поверхностная волна распространяется по спиральной траектории [1]. Продольная составляющая волнового вектора такой волны $k_{z}=\left(k^{2}-k_{r}^{2}\right)^{1 / 2}$, где $k=k_{0} n(\omega), k_{0}=\omega / c$ - волновое число в вакууме, $n(\omega)$ - показатель преломления материала световода, $k_{r}$ - поперечная (радиальная) компонента волнового вектора. Если угол ввода волны в световод достаточно близок к нормали к образующей цилиндра, то распространение волны вдоль его оси замедляется сколь угодно, вплоть до нулевых значений [2]. Схематически призменный ввод и вывод излучения представлен на рис. 1.

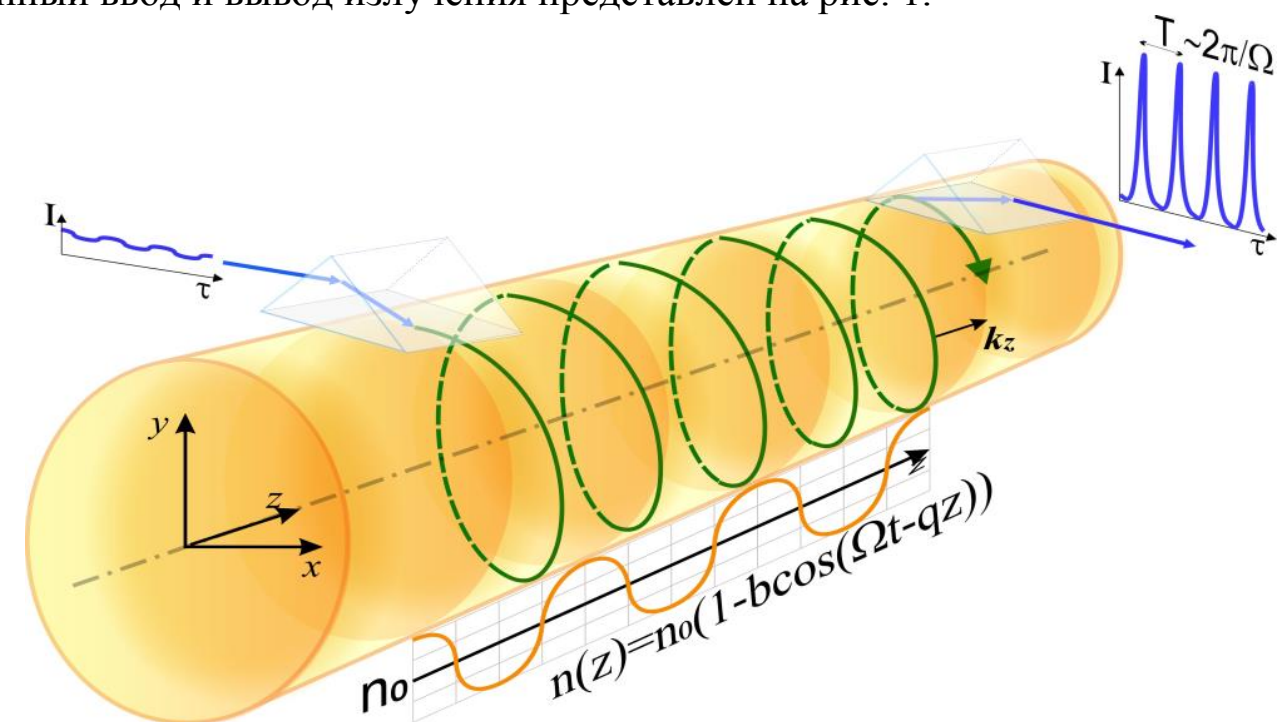

Рис.1. Траектория луча в цилиндрическом световоде, вводимого через призму и представляющего волну типа МШГ [3]; БВПП (снизу) и желаемый результат взаимодействия МШГ и БВПП мощное импульсное излучение на выходе.

Пусть в световоде распространяется еще БВПП (например, за счет возбуждения в нем акустической волны), тогда показатель преломления среды изменяется по закону (см. рис.1):

$$
n(t, z)=n_{0}[1-b \cos (\Omega t-q z)]
$$


где $\Omega$ - частота модуляции, $q=2 \pi / \Lambda-$ волновое число БВПП, $\Lambda$ - период пространственной неоднородности, $V_{a}=\Omega / q$ - скорость перемещения БВПП вдоль оси световода, $b=\Delta n / n_{0}$ - глубина модуляции ПП. $\Delta n-$ максимальное изменение ПП.

Уравнение, описывающее динамику временной огибающей туннелирующего волнового пакета, в координатах бегущего времени $\tau=t-\int_{0}^{z} d z / V_{z}(z)$ можно представить в виде:

$$
\frac{\partial A}{\partial z}-i D_{z} \frac{\partial^{2} A}{\partial \tau^{2}}+i R_{z}|A|^{2} A=i k b \gamma^{-1} \cos [\Omega(\tau-\delta \tau)] A,
$$

где параметр $\delta \tau=\left(V_{a}^{-1}-V_{z}^{-1}\right) z$ характеризует временную отстройку, связанную с разницей групповых скоростей МШГ и БВПП; $\gamma(z)=\left(1-k_{r}^{2} / k^{2}\right)^{1 / 2}-$ параметр продольного замедления туннелирующей волны. Продольная скорость волны, дисперсия групповых скоростей (ДГС) и нелинейность световода равны соответственно:

$$
V_{z}(z) \sim \gamma \frac{\partial \omega}{\partial k}, \quad D_{z}(z) \sim \frac{1}{\gamma} \frac{\partial^{2} k}{\partial \omega^{2}}, \quad R_{z} \sim n^{(2)} k / \gamma S_{e f},
$$

где $n^{(2)}-$ коэффициент материальной кубической нелинейности и $S_{e f}-$ эффективная площадь поверхностной моды. Если фазовая скорость туннелирующей волны примерно равна скорости перемещения БВПП ( $V_{z} \approx V_{a}$ ), то между туннелирующей поверхностной волной типа МШГ и БВПП происходит сильное резонансное взаимодействие, анализ которого выполняется в работе аналитическими и численными методами решения уравнений, описывающих динамику туннелирующего волнового пакета. Преобразование фоновой квазинепрерывной волны в импульсы показано на рис. 2.
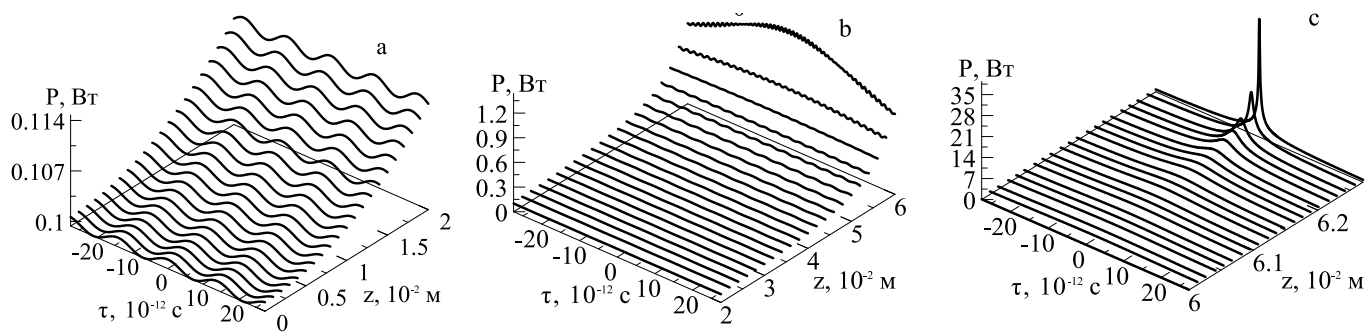

Рис. 2. Процесс формирования мощных импульсов в результате взаимодействия МШГ и БВПП на длине световода 6.3 см: начало процесса (a), формирование импульса (б) и финальное усиление импульса (в). Параметры для расчета: $d_{2}=10^{-26} \mathrm{c}^{2} / \mathrm{M}, R=10^{-2}\left(\mathrm{BT}^{\cdot \mathrm{M}}\right)^{-1}, P_{0}=0.1 \mathrm{BT}, \Omega=10^{9} \mathrm{c}^{-1}$, $\beta=10^{6} \mathrm{M}^{-1}, \gamma=4 \cdot 10^{-5}, \Delta n=10^{-4}$.

Работа выполнена при поддержке Минобрнауки России (проект 14.Z50.31.0015).

\section{Литература}

[1] Сычугов В.А., Магдич Л.Н., Торчигин В.П.,/ Квант. электроника. Т. 31. № 12. С. 1089 (2001)

[2] Sumetsky M., Opt. Express. V. 20. P. 22537 (2012)

[3] Торчигин В.П., Торчигин С.В., Квант. электроника. Т. 33. № 10. С. 913 (2003) 